\title{
Aerobic exercise and nano-curcumin supplementation improve inflammation in elderly females with metabolic syndrome
}

\author{
Ali Osali
}

\begin{abstract}
Background: Aging, inflammation, oxidative stress, and metabolic syndrome are the main important factors in brainderived neurotrophic factor (BDNF) level.

Aim: The aim of this research was to investigate the effect of 6-week aerobic exercise with moderate intensity and consumption of nano-curcumin on IL-6, IL-10 and BDNF in 60-65 year females with metabolic syndrome (MS).

Materials and methods: Forty-four women with metabolic syndrome (Mets) voluntarily took part in the present study. Participants were randomly divided into 4 groups of MetS exercise + Nano-Curcumin (MENC), MetS exercise (ME), MetS Nano-Curcumin (MNC), MetS control (MC). During the first week, MENC and ME groups participated in three sets of 10-min aerobic exercise training (AT) with a treadmill with 5-min rest parts between the sets. One minute was added to the duration of exercise sets weekly. Blood samples were collected before and after 6 weeks. IL-6, IL-10 and BDNF levels were measured by ELISA method. To analyze the data, Paired-samples t-test with the significance level of $(P \leq 0.05)$.

Results: IL-10 and BDNF concentrations significantly increased after a 6-week intervention ( $P \leq 0.05)$. Also, IL-6 serum levels significantly decreased $(P \leq 0.05)$. Besides, the results of the present study suggested that nano-curcumin supplementation significantly decreases serum concentrations of malondialdehyde (MDA), and hs-CRP in subjects with metabolic syndrome. In addition, the results of the present study suggested that nano-curcumin supplementation significantly increases serum concentrations of BDNF, IL-10, and total antioxidant capacity (TAC) in subjects with metabolic syndrome.
\end{abstract}

Conclusion: Findings show that both of the regular exercise and consumption of NanoCurcumin for 6 weeks reduce inflammation. Combination of these two leads to even more reduction of inflammation. The regular exercise led to a decrease at the fat percentage, which deceased IL-6 level and increased IL-10 level. So, this change led to increasing BDNF's levels.

Trial registration IRCT2017082335857N1 Registered 2017-11-16, https://en.irct.ir/trial/26971

Keywords: Aerobic exercise, Inflammation, Oxidative stress, Metabolic syndrome, Nano-curcumin

\begin{abstract}
Background
The metabolic syndrome characterized by the simultaneous presence of a number of cardiovascular risk factors such as obesity (particularly visceral adiposity), dyslipidemia, hypertriglyceridemia, low high-density lipoprotein cholesterol (HDL), hypertension, insulin resistance,
\end{abstract}


and impaired glucose tolerance [1,2]. Over the past two decades, the prevalence of metabolic syndrome has increased worldwide [1].

Furthermore, metabolic syndrome and obesity are associated with chronic low-grade systemic inflammation, particularly higher in old females [3]. Also, chronic low-grade inflammation is described as a significant increase in the systemic concentrations of circulating cytokines, such as tumor necrosis factor- $\alpha$ (TNF- $\alpha$ ), interleukin-1 $\beta$ (IL-1 $\beta$ ), and interleukin-6 (IL-6) [4]. The increased cytokine concentrations facilitate the intracellular influx of peripheral blood mononuclear cells (PBMC), which include lymphocytes and monocytes, constituting an important component of the immune system. In this sense, a synergistic relationship between lowgrade systemic inflammation and oxidative stress has also been postulated. Regarding this, cytokines and immune cells are able to trigger the production of reactive oxygen (ROS) and nitrogen species (RNS) to cope with defense activities [5].

In contrast, unbalanced cytokine release results in increased ROS production and oxidative stress-related conditions, such as atherosclerosis, stroke, renal and liver disorders, rheumatoid arthritis, auto-immune deficiencies, cancer, and Alzheimer's and Parkinson's diseases $[4,5]$. Therefore, the evidence points to an interaction among low-grade systemic inflammation and ROS overproduction, leading to these oxidative stress- and inflammation-related conditions previously mentioned. It has been recently stated that aerobic exercise training may be considered as the most effective nonpharmacological means for metabolic syndrome treatment [6]. However, despite several studies that demonstrated the antioxidant and anti-inflammatory effects of aerobic exercise training [7], other trials do not present inflammatory and oxidative profiles after a moderate-intensity aerobic exercise training in obese women with metabolic syndrome [8].

Medicinal herbs are used as supplements along with different training methods for improving health status. Curcumin is a bioactive yellow pigment with a polyphenolic structure that is present in turmeric (Curcuma longa L.). In recent years, beneficial reports have been published on the effects of curcumin, suggesting that curcumin is efficient and safe in the prevention and treatment of various diseases [9-11]. Curcumin interacts with various molecular targets including cytokines, growth factors, proteins, enzymes, and receptors [12]. Furthermore, this polyphenol has anti-inflammatory, antioxidant, and anti-tumor effects [13]. Although curcumin has been investigated in different clinical conditions, clinical trials evaluating its effect in individuals with metabolic syndrome are scarce [14].
Thus, the purpose of the present study was to investigate the effect of 6-week aerobic exercise training and nano-curcumin supplementation on inflammatory and oxidative stress parameters in old women with metabolic syndrome.

\section{Methods \\ Participants}

Forty-four females with metabolic syndrome aged 60-65 participated in this research after giving written informed consent. This research was conducted according to the guidelines laid down in the Declaration of Helsinki and was approved by the ethics committees of Semnan University of Medical Sciences and Health Services (IR.SEMUMS.REC.1396.107). The participants were recruited after an advertisement in the local hospitals. Participants were recruited only if they met the following criteria: female aged 60-65 years with the metabolic syndrome [15], non-smoking, no known history of cardiovascular disease, body mass index $(\mathrm{BMI})>30 \mathrm{~kg} / \mathrm{m}^{2}$, physically inactive $(<30 \mathrm{~min}$ of physical activity or exercise training per day), and a waist circumference $>88 \mathrm{~cm}$, which is associated with increased cardiovascular risk was defined as the cut-off $[16,17]$.

One is said to have the metabolic syndrome if he or she has central adiposity plus two or more of the following four factors [6]: (1) raised concentration of triglycerides: $\geq 150 \mathrm{mg} / \mathrm{dl}(1.7 \mathrm{mmol} / \mathrm{L})$ or specific treatment for this lipid abnormality; (2) reduced concentration of HDL cholesterol: $<40 \mathrm{mg} / \mathrm{dl}(1.03 \mathrm{mmol} / \mathrm{L})$ in men and $<50 \mathrm{mg} / \mathrm{dl}(1.29 \mathrm{mmol} / \mathrm{L})$ in women or specific treatment for this lipid abnormality; (3) raised blood pressure: systolic blood pressure $\geq 130 \mathrm{mmHg}$ or diastolic blood pressure $\geq 85 \mathrm{mmHg}$ or treatment of previously diagnosed hypertension; and (4) raised fasting plasma glucose concentration $\geq 100 \mathrm{mg} / \mathrm{dl}(5.6 \mathrm{mmol} / \mathrm{l})$ or previously diagnosed type 2 diabetes [18].

All subjects completed a questionnaire on physical activity, exercise, dietary intake, lifestyle, and health history prior to the study. The results of the questionnaire showed that the subjects were homogeneous in terms of these factors.

\section{Metabolic syndrome definition}

Metabolic syndrome was defined according to the criteria of the NCEP/ATP III to include individuals with any three or more of the following five components: (1) abdominal obesity (waist circumference $>102 \mathrm{~cm}$ for men or $>88 \mathrm{~cm}$ for women); (2) high TG $\geq 1.7 \mathrm{mmol} / \mathrm{L}$ $(150 \mathrm{mg} / \mathrm{dl})$; (3) low HDL-C: Men $<0.9 \mathrm{mmol} / \mathrm{L}(<40 \mathrm{mg} /$ $\mathrm{dl})$ or women $<1.0 \mathrm{mmol} / \mathrm{L} \quad(<50 \mathrm{mg} / \mathrm{dl})$; (4) high blood pressure (systolic $\mathrm{BP} \geq 130 \mathrm{~mm} \mathrm{Hg}$ or diastolic 
$\mathrm{BP} \geq 85 \mathrm{~mm} \mathrm{Hg}$ or treatment of hypertension), and high $\mathrm{FBG} \geq 6.1 \mathrm{mmol} / \mathrm{L}[17]$.

\section{Main trials}

Adopting a double-blind, placebo-controlled, and semiexperimental design, subjects were assigned to four equal groups: (1) placebo (control), aerobic exercise training (E), (2) nano-curcumin supplementation (NC), and (3) combined aerobic exercise training and nano-curcumin supplementation (ENC).

All subjects eligible to participate in the study attended a familiarization session where they were provided with information regarding the study design, testing, and supplementation protocols. None of the subjects had ingested nano-curcumin, or any other dietary supplements before initiation of the study.

The curcumin capsule was provided by the Theravalues Corporation (Tokyo, Japan). The curcumin capsule in the present study consisted of $10 \%$ nano-curcumin, $2 \%$ curcuminoids, $3.2 \%$ gum ghatti, $0.32 \%$ citric acid, $54.21 \%$ dextrin, and $30 \%$ maltose.

The participants were randomly assigned to either the nano-curcumin supplement ( $80 \mathrm{mg}$ per day) or placebo (80 mg per day maltodextrin) conditions. Both treatments were effervescent capsules, pre-packaged to be identical in appearance, size, and taste. Each group consumed one capsule per day for 6 weeks. During the treatment, subjects orally received $80 \mathrm{mg}$ of nano-curcumin or the same capsules of placebo either $1.5 \mathrm{~h}$ before exercise sessions or immediately after breakfast.

Each subject walked or ran at $65-75 \%$ heart rate reserve (HRR) on a treadmill for $3 \times 12-17 \mathrm{~min}$. Over the 6-week treatment, each week, 1 min was added to each set, beginning with $12 \mathrm{~min}$, so that the duration of each training set at the sixth week was $17 \mathrm{~min}$. Each session consisted of three sets of consecutive sessions with a 5-min rest interval between the sets. Heart Rate was monitored during the test using heart rate monitoring devices (Polar M400; Finland).

\section{Measurement of biochemical parameters}

Fasting venous blood samples were taken from the antecubital vein $24 \mathrm{~h}$ before and after exercise and supplementation protocols. The samples were taken twice, once at the beginning session and once again at the last session. For measuring serum blood markers, the samples were allowed to clot for $30 \mathrm{~min}$ at room temperature and then centrifuged at $3000 \mathrm{rpm}$ for $10 \mathrm{~min}$ at $4{ }^{\circ} \mathrm{C}$. Obtained serums were dispensed into micro tubes and stored at $-80{ }^{\circ} \mathrm{C}$ until the measurement of blood parameters. For measuring plasma blood markers, blood samples collected into tubes containing ethylene diamine tetra acetic acid (EDTA) were immediately centrifuged and stored at $-80{ }^{\circ} \mathrm{C}$ until the assay.

Plasma concentrations of interleukin-6 (IL-6), interleukin-10 (IL-10) and brain-derived neurotrophic factor (BDNF) were measured using eBioscience (Vienna, Austria) and Adipo Bioscience (USA) ELISA assay kits, respectively. The ferric reducing ability of plasma (FRAP) was used as a measure of total antioxidant capacity (TAC). Malondialdehyde (MDA) as the endproduct of lipid peroxidation was evaluated in the blood and tissue samples as described by the Esterbauer and Cheeseman method. Accordingly, MDA reacts with thiobarbituric acid (Sigma-Aldrich; St. Louis, Missouri, United States), and the pink pigment was produced, which has a maximum absorption at $532 \mathrm{~nm}$. Changes in plasma volume during the acute bout of exercise were calculated using the method outlined by Dill and Costill $[19,20]$.

\section{Statistical analysis}

Data were presented as mean $\pm \mathrm{SD}$. The KolmogorovSmirnov test was used to check for normality of distribution of all blood parameters. The distribution of these parameters did not differ significantly from normal. Using paired-samples t-test, the data were analyzed for the main effects of trial and time as well as the interaction of time $\times$ trial. Statistical significance was set at $\mathrm{P}<0.05$. Data analysis was performed using SPSS version18 software.

\section{Results}

The physical qualities of subjects were measured twice: at the first and the last sessions. The measures are as follows in the last session: expressed as mean \pm standard deviation [SD]: age, $62.3 \pm 1.23$ years; height, $164 \pm 7 \mathrm{~cm}$; body weight, $81.2 \pm 2.4 \mathrm{~kg}$; and body mass index (BMI), $29.5 \pm 1.2 \mathrm{~kg} / \mathrm{m}^{2}$.

The results of a within-group comparison of metabolic syndrome, weight, fat percentage, BMI, IL-6, IL-10, BDNF are listed in Tables $(1,2)$. The blood pressure, triglyceride, waist circumference, BMI, weight, body fat percentage, and IL-6 concentration were lower in the aerobic training group than in the placebo group after the intervention $(\mathrm{P}<0.01)$ Tables $(1,2)$. Also, the results of the present study suggested that nano-curcumin supplementation significantly decreases serum concentrations of TNF-a, IL-6, MDA, and hs-CRP in subjects with metabolic syndrome. In addition, the results of the present study suggested that nano-curcumin supplementation significantly increases serum concentrations of BDNF, IL-10, and TAC in subjects with metabolic syndrome. 
Table 1 Biochemical variables in nano-Curcumin, aerobic training, combined and Placebo groups

\begin{tabular}{|c|c|c|c|c|c|c|c|c|}
\hline \multirow[t]{2}{*}{ Variable } & \multicolumn{8}{|l|}{ Groups } \\
\hline & ENC & $P$ & E & $P$ & $\mathrm{NC}$ & $P$ & $\mathrm{C}$ & $P$ \\
\hline \multicolumn{9}{|c|}{$\mathrm{SBP}(\mathrm{mmHg})$} \\
\hline Pre & $145.4 \pm 9.1$ & 0.001 & $145.2 \pm 15.2$ & 0.001 & $146.9 \pm 11.7$ & 0.001 & $152 \pm 14.69$ & 0.68 \\
\hline Post & $120 \pm 2.61$ & & $137.7 \pm 7.89$ & & $132.1 \pm 10.26$ & & $152.7 \pm 11.47$ & \\
\hline \multicolumn{9}{|c|}{ Waist circumference $(\mathrm{cm})$} \\
\hline Pre & $103.5 \pm 6.84$ & 0.001 & $105 \pm 10.8$ & 0.001 & $102.4 \pm 5.69$ & 0.32 & $104.8 \pm 6.97$ & 0.9 \\
\hline Post & $98.75 \pm 5.86$ & & $101.08 \pm 5.61$ & & $103.9 \pm 6.87$ & & $104.2 \pm 6.47$ & \\
\hline \multicolumn{9}{|c|}{ Glucose (mg/dl) } \\
\hline Pre & $172.5 \pm 52.7$ & 0.001 & $170.2 \pm 50.5$ & 0.001 & $178.6 \pm 52.8$ & 0.001 & $183.1 \pm 52.8$ & 0.75 \\
\hline Post & $108.83 \pm 7.06$ & & $125.9 \pm 27.2$ & & $111.4 \pm 9.59$ & & $182.1 \pm 51.34$ & \\
\hline \multicolumn{9}{|c|}{ Triglyceride (mg/dl) } \\
\hline Pre & $232.1 \pm 62.7$ & 0.001 & $223.08 \pm 64.5$ & 0.001 & $215.6 \pm 50.4$ & 0.001 & $225.8 \pm 69.2$ & 0.01 \\
\hline Post & $161.6 \pm 39.9$ & & $197.7 \pm 69.2$ & & $164.6 \pm 24.13$ & & $180.3 \pm 55.2$ & \\
\hline \multicolumn{9}{|c|}{$\mathrm{HDL}(\mathrm{mg} / \mathrm{dl})$} \\
\hline Pre & $46.66 \pm 7.03$ & 0.001 & $47.25 \pm 5.22$ & 0.001 & $46.7 \pm 3.74$ & 0.001 & $45.6 \pm 5.18$ & 0.08 \\
\hline Post & $56.91 \pm 7.26$ & & $53.33 \pm 4.35$ & & $52.6 \pm 3.2$ & & $44.7 \pm 2.79$ & \\
\hline \multicolumn{9}{|c|}{ BMI $\left(\mathrm{kg} \mathrm{m}^{-2}\right)$} \\
\hline Pre & $31.24 \pm 3.12$ & 0.001 & $32.22 \pm 2.46$ & 0.001 & $29.54 \pm 2.67$ & 0.02 & $29.02 \pm 1.56$ & 0.11 \\
\hline Post & $29.91 \pm 3.25$ & & $31.27 \pm 2.39$ & & $29.66 \pm 2.6$ & & $29.11 \pm 1.51$ & \\
\hline \multicolumn{9}{|c|}{ Weight (kg) } \\
\hline Pre & $77.01 \pm 3.65$ & 0.001 & $77.67 \pm 2.95$ & 0.001 & $76.12 \pm 5.51$ & 0.03 & $74.72 \pm 5.32$ & 0.11 \\
\hline Post & $73.69 \pm 4.11$ & & $75.38 \pm 2.98$ & & $76.43 \pm 5.46$ & & $74.97 \pm 4.32$ & \\
\hline \multicolumn{9}{|c|}{ Body fat (\%) } \\
\hline Pre & $37.96 \pm 3.07$ & 0.001 & $37.2 \pm 3.67$ & 0.001 & $36.7 \pm 4.11$ & 0.01 & $37.4 \pm 4.45$ & 0.001 \\
\hline Post & $33.5 \pm 2.96$ & & $35.08 \pm 4.01$ & & $35.6 \pm 4.14$ & & $38.01 \pm 4.16$ & \\
\hline
\end{tabular}

$B M I$ body mass index, SBP systolic blood pressure, IL-6 interleukin-6, IL-10 interleukin-10, BDNF brain-derived neurotrophic factor, TAC total antioxidant capacity, MDA malondialdehyde, CRP C-reactive protein

\section{Discussion}

The moderate-intensity aerobic exercise training induced total body fat percentage decrease in women with metabolic syndrome. Changes in total body fat mass are likely connected with the decreased inflammatory cytokines levels $[16,21]$. In addition, the adipose tissue is considered not only a fat reservoir but also an endocrine tissue associated with insulin sensitivity, endocrine systems, and inflammation [16]. In fact, moderate-intensity aerobic exercise training increases energy expenditure and lipolysis in subcutaneous and intramuscular fat stores accumulated in metabolic syndrome patients.

Elevated white adipose tissue, hyperglycemia, endothelial ROS production, and inadequate antioxidant defenses are connected to oxidative stress in obesity [22]. In the current study, the moderate-intensity aerobic exercise training induced reduction on oxidative damage (MDA) indicator with a concomitant increase in antioxidant status (TAC) in metabolic syndrome women, indicating oxidative balance. The long-term exercise-induced adaptations of oxidative stress are similar to the general principles of exercise training. This suggests that the chronic exposure to pro-oxidant agents such as bouts of moderate aerobic exercises results in the upregulation of antioxidant defenses, providing a balance between the ROS-induced damage and the antioxidant systems [23].

This study found that a 6-week moderate-intensity aerobic exercise training reduced IL- 6 and CRP serum levels, while IL-10 and BDNF increased. Some mechanisms have been proposed to explain how exercise training may reduce chronic low-grade inflammation in MS. It is known that in addition to the adipose tissue, the working skeletal muscle is a potential source of cytokines. The IL-6 produced by myocytes through AMP-activated protein kinase (AMPK) activation at sufficient AT intensities presents anti-inflammatory effects as opposed to IL- 6 secreted by adipose tissue, promoting the release of IL-10 and interleukin-1 receptor antagonist (IL-1RA), with a concomitant inhibition of TNF- $\alpha$ production during the effort and some hours after the exercise sessions. Another possible mechanism is the reduced expression of the toll-like receptors and nuclear transcription factor $\mathrm{kB}$ 
Table 2 Biochemical variables in nano-Curcumin, aerobic training, combined and Placebo groups

\begin{tabular}{|c|c|c|c|c|c|c|c|c|}
\hline \multirow[t]{2}{*}{ Variable } & \multicolumn{8}{|l|}{ Groups } \\
\hline & ENC & $P$ & $E$ & $P$ & NC & $P$ & C & $P$ \\
\hline \multicolumn{9}{|c|}{ IL-6 (pg/mL) } \\
\hline Pre & $18.88 \pm 2.39$ & 0.001 & $18.05 \pm 2.34$ & 0.001 & $19 \pm 2.58$ & 0.001 & $19.16 \pm 2.68$ & 0.47 \\
\hline Post & $13.65 \pm 2.4$ & & $14.92 \pm 2.38$ & & $15.68 \pm 2.38$ & & $18.68 \pm 2.71$ & \\
\hline \multicolumn{9}{|c|}{ IL-10 (pg/mL) } \\
\hline Pre & $7.74 \pm 1.17$ & 0.001 & $7.59 \pm 1.16$ & 0.001 & $8.1 \pm 1.36$ & 0.001 & $8.23 \pm 1.31$ & 0.09 \\
\hline Post & $10.97 \pm 0.38$ & & $6.69 \pm 0.71$ & & $10.72 \pm 1.41$ & & $7.85 \pm 1.15$ & \\
\hline \multicolumn{9}{|c|}{ BDNF (pg/mL) } \\
\hline Pre & $115.33 \pm 15.31$ & 0.001 & $113.16 \pm 14.6$ & 0.001 & $110.6 \pm 15.49$ & 0.001 & $107 \pm 17.61$ & 0.26 \\
\hline Post & $273.5 \pm 15.86$ & & $172.08 \pm 9.6$ & & $198.5 \pm 15.7$ & & $105.2 \pm 16.14$ & \\
\hline \multicolumn{9}{|c|}{ TAC (mmol/L) } \\
\hline Pre & $0.582 \pm 0.32$ & 0.001 & $0.504 \pm 0.48$ & 0.001 & $0.541 \pm 0.21$ & 0.001 & $0.518 \pm 0.41$ & 0.58 \\
\hline Post & $1.22 \pm 0.62$ & & $1.28 \pm 0.68$ & & $1.31 \pm 0.78$ & & $0.521 \pm 0.8$ & \\
\hline \multicolumn{9}{|c|}{ MDA (nmol/dL) } \\
\hline Pre & $2.68 \pm 0.71$ & 0.001 & $2.74 \pm 0.78$ & 0.001 & $2.59 \pm 0.82$ & 0.001 & $2.79 \pm 0.61$ & 0.61 \\
\hline Post & $1.47 \pm 0.62$ & & $1.42 \pm 0.68$ & & $1.32 \pm 0.78$ & & $2.81 \pm 0.8$ & \\
\hline \multicolumn{9}{|c|}{ CRP (pg/mL) } \\
\hline Pre & $2.31 \pm 0.72$ & 0.001 & $2.24 \pm 0.67$ & 0.001 & $2.26 \pm 0.58$ & 0.001 & $2.29 \pm 0.71$ & 0.74 \\
\hline Post & $1.21 \pm 0.84$ & & $1.34 \pm 0.61$ & & $1.18 \pm 0.67$ & & $2.31 \pm 0.79$ & \\
\hline
\end{tabular}

$B M I$ body mass index, SBP systolic blood pressure, IL-6 interleukin-6, IL-10 interleukin-10, BDNF brain-derived neurotrophic factor, TAC total antioxidant capacity, MDA malondialdehyde, CRP C-reactive protein

(NFkB) on monocytes and macrophages, probably linked to hormonal and heat shock protein levels, increased lipolysis, and reduced number of monocytes reported in some studies. Moreover, recent evidence shows that exercise training may increase angiogenesis and blood supply, thereby reducing hypoxia and the associated inflammation in adipose tissue [21].

Previous studies concerning serum or plasma cytokine levels and their concentrations have evaluated the acute effects of exercise [24]. Based on the findings reported in previous as well as the present study, it could be hypothesized that major weight loss connected to exercise training is necessary to modulate inflammatory indicators levels $[25,26]$. Also, we found a significant reduction of IL-6 and CRP in women with metabolic syndrome. In this regard, some of the previous studies have shown significant reductions in C-reactive protein concentration which is another important indicator of systemic inflammation, following nano-curcumin intake and supplementation [14].

Several studies have reported positive effects of nanocurcumin supplementation in the prevention and treatment of obesity, atherosclerosis, diabetes, and metabolic syndrome [27]. Nano-curcumin is involved in several mechanisms inhibiting inflammatory cytokines production from adipose tissue. Research shows that nano-curcumin can suppress vital transcription factors such as nuclear factor kappa B, resulting in inhibition of inflammatory cytokines gene expression [28]. Another possible mechanism is suppressing inflammatory cytokines production through down-regulation of intracellular signaling protein kinases by nano-curcumin. Moreover, nano-curcumin reduces macrophage accumulation in adipose tissue by suppressing the expression of inflammatory cytokines and subsequent inhibition of obesityinduced inflammatory response [29]. Aside from direct inhibitory effects on cytokine production and release, mitigation of several components of metabolic syndromes, such as obesity, insulin resistance, dyslipidemia, hyperglycemia, and hypertension, may be responsible for the decreased levels of pro-inflammatory cytokines following nano-curcumin supplementation.

\section{Conclusions}

In conclusion, training with or without the nano-curcumin supplementation and the supplementation alone could improve inflammation, BDNF concentration, and stress oxidative indices, as well as the glycemic level, in the elderly females with metabolic syndrome. Besides, nano-curcumin supplementation has positive effects for the improvement of stress oxidative index. Moreover, aerobic exercises with or without the nano-curcumin supplementation and the supplementation alone could improve total antioxidant capacity and hsCRP. Overall, 
performing aerobic exercises with nano-curcumin supplementation is suggested as a helpful supplementary treatment for decreasing the inflammation in patients with metabolic syndrome. Needless to say, more studies are needed in this area to determine the best dose of supplementation and exercise intensity and volume.

\begin{abstract}
Abbreviations
AMPK: AMP-activated protein kinase; AT: Aerobic exercise training; BDNF: Brain-derived neurotrophic factor; NC: Nano-curcumin supplementation; EDTA: Amine tetra acetic acid; E: Exercise training; ENC: Exercise training and nano-curcumin supplementation; FRAP: Ferric reduction ability of plasma; HDL: Low high-density lipoprotein cholesterol; HRR: Heart rate reserve; IL-1 $\beta$ : Interleukin-1 $\beta$; IL-6: Interleukin-6; MC: Metabolic syndrome control; MNC: Metabolic syndrome nano-curcumin; MDA: Malondialdehyde; ME: Metabolic syndrome exercise; MENC: Metabolic syndrome exercise + nano-curcumin; MetS: Metabolic syndrome; NFKB: Nuclear transcription factor KB; PBMC: Peripheral blood mononuclear cells; RNS: Reactive nitrogen species; ROS: Reactive oxygen species; RPE: Rating of perceived exertion; TAC: Total Antioxidant Capacity; TNF-a:Tumor necrosis factor-a.
\end{abstract}

\section{Acknowledgements}

The author would like to thank the subjects that participated in this study.

\section{Authors' contributions}

The study was designed by AO; data were collected and analyzed by AO; data interpretation and manuscript preparation were undertaken by AO. The author read and approved the final manuscript.

\section{Funding}

This article is taken from research project number 97///ER/1920, sponsored by University of Bonab, Iran.

\section{Availability of data and materials}

Not applicable. Conclusions of the manuscript are based on relevant data sets available in the manuscript.

\section{Ethics approval and consent to participate}

This study was approved by the Semnan University Medical Sciences Review Board for the protection of human subjects (Approval date, 2017-07-12).

\section{Consent for publication}

All participants were aware during the informed consent process that the results of this study may be published.

\section{Competing interests}

The authors declare that they have no competing interests.

Received: 16 October 2019 Accepted: 15 March 2020

Published online: 30 March 2020

\section{References}

1. Nolan PB, Carrick-Ranson G, Stinear JW, Reading SA, Dalleck LC. Prevalence of metabolic syndrome and metabolic syndrome components in young adults: a pooled analysis. Prev Med Rep. 2017;7:211-5.

2. Farinha JBSF, Stefanello ST, Cardoso MS, Nunes LS, Barcelos RP, et al. Response of oxidative stress and inflammatory biomarkers to a 12-week aerobic exercise training in women with metabolic syndrome. Sports Med-Open. 2015;1(1):19.

3. Mathur N, Pedersen BK. Exercise as a mean to control low-grade systemic inflammation. Mediators Inflamm. 2009. https://doi. org/10.1155/2008/109502.

4. Esser N, Legrand-Poels S, Piette J, Scheen AJ, Paquot N. Inflammation as a link between obesity, metabolic syndrome and type 2 diabetes. Diab Res Clin Pract. 2014;105(2):141-50.
5. Devries MC, Hamadeh MJ, Glover AW, Raha S, Samjoo IA, Tarnopolsky MA. Endurance training without weight loss lowers systemic, but not muscle, oxidative stress with no effect on inflammation in lean and obese women. Free Radic Biol Med. 2008;45(4):503-11.

6. Otani H. Oxidative stress as pathogenesis of cardiovascular risk associated with metabolic syndrome. Antioxid Redox Signal. 2011;15(7):1911-26.

7. Gleeson M, Bishop NC, Stensel DJ, Lindley MR, Mastana SS, Nimmo MA The anti-inflammatory effects of exercise: mechanisms and implications for the prevention and treatment of disease. Nat Rev Immunol. 2011;11(9):607.

8. de Oliveira VN, Bessa A, Jorge MLMP, Oliveira RJdS, de Mello MT, Agostin $\mathrm{GG}$, et al. The effect of different training programs on antioxidant status, oxidative stress, and metabolic control in type 2 diabetes. Appl Physiol Nutr Metab. 2012:37(2):334-44.

9. Sahebkar A. Are curcuminoids effective C-reactive protein-lowering agents in clinical practice? Evidence from a meta-analysis. Phytother Res. 2014;28(5):633-42.

10. Mohammadi A, Sahebkar A, Iranshahi M, Amini M, Khojasteh R, GhayourMobarhan M, et al. Effects of supplementation with curcuminoids on dyslipidemia in obese patients: a randomized crossover trial. Phytother Res. 2013;27(3):374-9.

11. Panahi Y, Hosseini MS, Khalili N, Naimi E, Simental-Mendía LE, Majeed M, et al. Effects of curcumin on serum cytokine concentrations in subjects with metabolic syndrome: a post hoc analysis of a randomized controlled trial. Biomed Pharmacother. 2016:82:578-82.

12. Zhou H, Beevers CS, Huang S. The targets of curcumin. Curr Drug Targets. 2011;12(3):332-47.

13. Kowluru RA, Kanwar M. Effects of curcumin on retinal oxidative stress and inflammation in diabetes. Nutr Metab. 2007:4(1):8.

14. Panahi Y, Hosseini MS, Khalili N, Naimi E, Majeed M, Sahebkar A. Antioxidant and anti-inflammatory effects of curcuminoid-piperine combination in subjects with metabolic syndrome: a randomized controlled trial and an updated meta-analysis. Clin Nutr. 2015;34(6):1101-8.

15. Expert Panel on Detection E. Executive summary of the third report of the national cholesterol education program (NCEP) expert panel on detection, evaluation, and treatment of high blood cholesterol in adults (Adult Treatment Panel III). JAMA. 2001;285(19):2486.

16. Pedersen BK. Anti-inflammatory effects of exercise: role in diabetes and cardiovascular disease. Eur J Clin Invest. 2017;47(8):600-11.

17. Ridker PM, Buring JE, Cook NR, Rifai N. C-reactive protein, the metabolic syndrome, and risk of incident cardiovascular events: an 8-year follow-up of 14719 initially healthy American women. Circulation. 2003;107(3):391-7.

18. Ford ES. Prevalence of the metabolic syndrome defined by the international diabetes federation among adults in the US. Diab Care. 2005;28(11):2745-9.

19. Patanella AKZM, Quaranta D, Nociti V, Frisullo G, Gainotti G, et al. Correlations between peripheral blood mononuclear cell production of BDNF, TNF-alpha, IL-6, IL-10 and cognitive performances in multiple sclerosis patients. J Neurosci Res. 2010;88(5):1106-12

20. Lee SS. The effects of 12 weeks regular aerobic exercise on brain-derived neurotrophic factor and inflammatory factors in juvenile obesity and type 2 diabetes mellitus. J Phys Ther Sci. 2014;26:1199-204.

21. You T, Arsenis NC, Disanzo BL, LaMonte MJ. Effects of exercise training on chronic inflammation in obesity. Sports Med. 2013:43(4):243-56.

22. Vincent HK, Taylor AG. Biomarkers and potential mechanisms of obesityinduced oxidant stress in humans. Int J Obes. 2006:30(3):400.

23. Fisher-Wellman K, Bloomer RJ. Acute exercise and oxidative stress: a 30 year history. Dyn Med. 2009;8(1):1.

24. Abdizadeh $L$, Jafari A, Armanfar M. Effects of short-term coenzyme Q10 supplementation on markers of oxidative stress and inflammation after downhill running in male mountaineers. Sci Sports. 2015:30(6):328-34.

25. Sheu WHH, Chang TM, Lee WJ, Ou HC, Wu CM, Tseng LN, et al. Effect of weight loss on proinflammatory state of mononuclear cells in obese women. Obesity. 2008;16(5):1033-8.

26. Nunes PRP, Barcelos LC, Oliveira AA, Júnior RF, Martins FM, Orsatti CL, et al. Effect of resistance training on muscular strength and indicators of abdominal adiposity, metabolic risk, and inflammation in postmenopausal women: controlled and randomized clinical trial of efficacy of training volume. Age. 2016:38(2):40 
27. Aggarwal BB. Targeting inflammation-induced obesity and metabolic diseases by curcumin and other nutraceuticals. Annu Rev Nutr. 2010;30:173-99.

28. Shehzad A, Khan S, Sup Lee Y. Curcumin molecular targets in obesity and obesity-related cancers. Future Oncol. 2012;8(2):179-90.

29. Jurenka JS. Anti-inflammatory properties of curcumin, a major constituent of Curcuma longa: a review of preclinical and clinical research. Altern Med Rev. 2009;14(2):141-53.

\section{Publisher's Note}

Springer Nature remains neutral with regard to jurisdictional claims in published maps and institutional affiliations.
Ready to submit your research? Choose BMC and benefit from:

- fast, convenient online submission

- thorough peer review by experienced researchers in your field

- rapid publication on acceptance

- support for research data, including large and complex data types

- gold Open Access which fosters wider collaboration and increased citations

- maximum visibility for your research: over $100 \mathrm{M}$ website views per year

At BMC, research is always in progress.

Learn more biomedcentral.com/submissions 